1 Universidade Federal da Bahia (UFBA) - Salvador (BA), Brasil. Orcid: https://orcid org/0000-0003-12264356

adriele.caldas@hotmail.com

2 Universidade Federal da Bahia (UFBA) - Salvador (BA), Brasil.

Orcid: https://orcid. org/0000-0002-95239561

dncnogueira@hotmail.com

3 Universidade Federal da Bahia (UFBA) - Salvador (BA), Brasil.

Orcid: https://orcid org/0000-0002-8255-

1230

sgb@ufba.br

4 Universidade do Estado da Bahia (Uneb) Salvador (BA), Brasil. Orcid: https://orcid. org/0000-0002-2561$088 \mathrm{X}$

thais.aranha@gmail.com

5 Universidade Federal da Bahia (UFBA) - Salvador (BA), Brasil.

Orcid: https://orcid org/0000-0002-14768649

schaves@ufba.br

\section{A política de saúde bucal em um município baiano: os agentes da burocracia estatal}

\author{
The oral health policy in a municipality of Bahia: the agents of state \\ bureaucracy
}

Adriele Souza Caldas', Denise Nogueira Cruz ${ }^{\mathbf{2}}$, Sandra Garrido de Barros ${ }^{\mathbf{3}}$, Thais Regis Aranha Rossi $\mathbf{4}^{4}$ Sônia Cristina Lima Chaves ${ }^{5}$

DOI: $10.1590 / 0103-1104201811908$

RESUMO Este estudo buscou caracterizar os Coordenadores de Saúde Bucal (CSB) envolvidos na implantação da Política Nacional de Saúde Bucal (PNSB) em um município baiano, caso exemplar, entre 1997 e 2015. Foi realizado um estudo de caso com abordagem qualitativa, baseado no referencial bourdieusiano, por meio de entrevistas em profundidade com seis CSB, com média de 45 anos. Foram analisadas as suas trajetórias profissionais a partir das categorias: origem social, formação profissional, trajetória e inserção profissional e trajetória no campo burocrático. A maioria graduou-se em instituições públicas e apresentou trajetória ascendente no campo burocrático. A inserção na gestão foi influenciada pelas disposições, pela rede de relações e pelo desempenho profissional na Estratégia Saúde da Família (ESF). A qualificação profissional parece ser aspecto diferenciador. A pós-graduação em saúde coletiva representou maior possibilidade de inserção na ESF. A equipe gestora manteve o exercício da clínica. O apoio da gestão municipal e da saúde foi ressaltado por quase todos os entrevistados. A PNSB contribuiu para expansão da rede de saúde bucal, contudo, as principais proposições já estavam implantadas anteriormente. Evidencia-se a importância da gestão na implantação da PNSB e recomenda-se a realização de análise semelhante de outros casos para identificação de regularidades que contribuam para a explicação dos diferentes graus de implementação dessa política.

PALAVRAS-CHAVE Saúde bucal. Política de saúde. Política pública. Gestor de saúde.

ABSTRACT This study aimed to characterize Oral Health Coordinators $(\mathrm{OHC})$ involved in the implantation of the Brazilian Oral Health Policy (BOHP) in a municipality of Bahia, exemplary case, between 1997-2015. A qualitative approach case study was carried out, based on the Bourdieu theoretical, through in-depth interviews with six $\mathrm{OHC}$, with an average of 45 years of age. Their professional trajectories were analyzed from the following categories: social origin, professional training, professional trajectory and insertion, and trajectory in the bureaucratic field. The majority of them graduated from public institutions and presented an upward trajectory in the bureaucratic field. The insertion in management was influenced by dispositions, network relations, and professional performance in Family Health Strategy (FHS). Professional qualification seems to be a differentiating aspect. Post-graduation in public health represented a greater possibility of insertion in the FHS. The management team maintained clinical practice. The support of municipal management and health was highlighted by almost all interviewees. The BOHP contributed to the 
expansion of the oral health network, however, the main propositions were implanted previously. The importance of management in the BOHP implementation is evident and it is recommended to carry out similar analysis of other cases to identify regularities that contribute to the explanation of the different degrees of BOHP implementation.

KEYWORDS Oral health. Health policy. Public policy. Health manager.

\section{Introdução}

Política pode ser definida como a 'arte de governo' ou a ciência que estuda qualquer ação, situação, que gira em torno da cidade, do Estado'. A conformação de um conjunto de interesses, comuns ou não, que se referem ao coletivo, caracteriza as políticas públicas' $\mathbf{1}$ O caráter público dessas políticas se dá não apenas pela produção de bens comuns, mas também pelo seu cunho impositivo; ou seja, o Estado detém o controle da resposta à demanda das políticas, concebida pela sociedade ou pela burocracia' ${ }^{1}$. Nessa direção, a dimensão impositiva das políticas públicas remete à ideia de Estado como o detentor do "monopólio legítimo da coação física para manutenção das ordenações"2(204), acreditando que quem está no Estado tem o poder, a apropriação de guiar a política.

Dentre as políticas públicas, destaca-se a política de saúde que revela a ação ou omissão do Estado diante dos problemas de saúde dos indivíduos e da sociedade ${ }^{3}$. No Brasil, observa-se, em determinadas conjunturas, uma omissão do Estado em relação às necessidades de saúde da população, sendo o Sistema Único de Saúde (SUS) uma das maiores políticas públicas em vigência no País ${ }^{4}$.

O SUS é uma 'política de Estado' resultante do Movimento da Reforma Sanitária Brasileira e que tem como princípios doutrinários a universalidade, equidade e integralidade da atenção ${ }^{5,6}$. A inscrição da 'saúde como direito de todos e dever do Estado’ é um dos grandes avanços da Constituição Cidadã de 1988.
Desde a conformação do SUS, apesar de persistirem as dificuldades na garantia de fontes estáveis de financiamento7 ${ }^{7}$ é possível identificar importantes conquistas, como as políticas de redirecionamento em saúde mental $^{8}$, saúde materno-infantil ${ }^{9}$, urgências $^{10}$ e, particularmente, saúde bucal ${ }^{11}$.

A Política Nacional de Saúde Bucal (PNSB) de $2004^{11}$ propõe o fortalecimento das ações de promoção e proteção à saúde bucal. Entre outros propósitos, a PNSB/2004 orienta a implementação de ações para expansão da fluoretação das águas de abastecimento público, ampliação do acesso aos serviços, fortalecimento das atividades de educação em saúde e garantia da continuidade do cuidado nos diferentes níveis de atenção ${ }^{11}$.

A análise da implementação de saúde bucal em Salvador ${ }^{12}$ e da atenção especializada em dois municípios baianos ${ }^{13}$ aponta a gestão como elemento fundamental na construção dessas políticas. Entretanto, ainda são escassos estudos no que tange à análise dos agentes sociais, entre eles, os gestores, que participam do processo de implementação e de como influenciaram tais políticas. No caso dessas políticas, o locus em que se operam formulação, implantação e avaliação destas é o campo burocrático ${ }^{14}$.

Desse modo, as contribuições dos estudos sobre a implementação da PNSB/2004 ${ }^{12,13}$, ainda que relevantes, apontam para a necessidade de novas investigações. Apesar de identificarem a relevância do campo burocrático para análise da implementação dessa política, 
esses estudos não se aprofundaram na análise dos agentes desse campo.

Nesse sentido, o objetivo deste trabalho foi caracterizar os agentes do campo burocrático envolvidos com a implantação da PNSB/2004 em um município baiano no período entre 1997 e 2015, analisando a origem e a trajetória social e profissional desses agentes.

\section{Material e métodos}

Foi realizado um de estudo de caso, com abordagem qualitativa ${ }^{15}$, fundamentado no referencial bourdieusiano, especialmente, nos conceitos de capital (cultural, econômico, político, burocrático, social, entre outros), campo, agente, trajetória e habitus ${ }^{\mathbf{1 4}}$. Tais construções podem auxiliar a compreensão das relações entre agentes de diferentes espaços sociais na formulação de políticas públicas, a exemplo das análises realizadas por Pinell16.

Os agentes estão posicionados no espaço social. Ao seu interior, coexistem diferentes subespaços em que agentes se articulam em torno de interesses específicos, como os Espaços: da Saúde Coletiva ${ }^{\mathbf{1 7}}$, Aids ${ }^{\mathbf{1 8}}$, do Programa de Incentivo Fiscal à Alimentação do Trabalhador/Programa de Alimentação do Trabalhador (Pifat/PAT) ${ }^{19}$, de formulação das políticas de saúde bucal ${ }^{20}$ e da saúde bucal coletiva ${ }^{21}$, mas também o campo científico, artístico e burocrático. O campo seria um subespaço social dotado de autonomia relativa em relação a outros subespaços, ao interior do qual os agentes confrontam seus diferentes pontos de vista em relação às questões em disputa $^{14}$. A posição do agente em um determinado campo guarda relação com o volume de capital que este possui.

O campo burocrático é um espaço em que seus agentes e instituições possuem o poder de falar em nome do Estado, de modo que passam a ser detentores do metapoder garantido pelo Estado $^{22}$. O campo burocrático seria:

um universo cuja lei fundamental é o serviço público; universo no qual os agentes sociais não têm interesse pessoal e sacrificam seus próprios interesses ao público, ao serviço público, ao universal14(149)

Investigações cujo objeto foi a gênese de políticas públicas confirmaram a importância dos agentes do campo burocrático para a formulação e desenvolvimento dessas políticas a partir da análise das trajetórias profissional e social desses agentes 18-20,23.

A análise das trajetórias dos agentes que atuaram no processo de implementação de uma dada política de saúde pode explicar a influência destes na sua formulação e desenvolvimento. Articulada aos conceitos bourdieusianos, pode apontar outros elementos para explicar diferenças na implementação das políticas de saúde bucal nos municípios.

A trajetória dos agentes é entendida como a "série das posições sucessivamente ocupadas"24(292) no espaço social. É, portanto, resultante das disposições de cada agente, dos constrangimentos incorporados pelo habitus dos diferentes espaços no qual ele tem inserção: "uma maneira singular de percorrer o espaço social”24(292). Por conseguinte, as trajetórias estão relacionadas com os habitus, ou com as características dos agentes que determinam as suas escolhas, gerando práticas distintas e distintivas ${ }^{14}$.

Para realização deste estudo, foi selecionado um município de grande porte do interior da Bahia, cuja população distribuía-se entre a zona rural e a urbana. A escolha do município se deu em função do seu pioneirismo na inserção da saúde bucal na Estratégia Saúde da Família (ESF) ${ }^{\mathbf{2 5}, 26}$, antes do estabelecimento de repasse financeiro federal.

Foram realizadas entrevistas em profundidade com Coordenadores de Saúde Bucal (CSB) do período entre 1997 e 2015, entendidos aqui como agentes do campo burocrático. A definição do ano inicial do estudo relacionou-se com dois aspectos: 1) em 1997, teve início o 'governo participativo' conduzido por um partido político que se manteve na gestão 
municipal até 2016; 2) em 1998, o município alcançou a gestão plena do sistema de saúde. Todas as entrevistas foram realizadas entre junho e dezembro de 2015.

Foram identificados, por meio de análise documental, sete diferentes coordenadores no período analisado, incluindo os coordenadores da atenção primária e do Centro de Especialidades Odontológicas (CEO) (quadro 1). Um dos CSB não foi entrevistado por incompatibilidade de agenda.

Quadro 1. Período de atuação dos agentes na gestão da saúde bucal e da atenção especializada em saúde bucal de um município baiano, 1997-2016

\begin{tabular}{|c|c|c|c|c|}
\hline \multirow[t]{2}{*}{ Período } & \multicolumn{2}{|c|}{ Gestão da Saúde Bucal } & \multicolumn{2}{|c|}{ Gestão da atenção especializada em Saúde Bucal } \\
\hline & Agente & Cargo & Agente & Cargo \\
\hline 1997-1998 & CSB6 & Coordenador da Divisão de Odontologia & & \\
\hline 1998-1999 & \multirow[t]{6}{*}{ CSB1 } & Coordenador de saúde bucal & & \\
\hline 1999-2000 & & & \multirow[t]{5}{*}{ CSB1 } & \multirow{5}{*}{$\begin{array}{l}\text { Coordenador da atenção especia- } \\
\text { lizada em saúde bucal }\end{array}$} \\
\hline $2000-2001$ & & & & \\
\hline 2001-2002 & & & & \\
\hline $2002-2003$ & & & & \\
\hline $2003-2004$ & & & & \\
\hline 2004-2005 & \multirow[t]{7}{*}{ CSB2 } & \multirow[t]{7}{*}{ Coordenador de saúde bucal } & \multirow[t]{6}{*}{ CSB1 } & \multirow{6}{*}{$\begin{array}{l}\text { Coordenador da atenção especia- } \\
\text { lizada em saúde bucal }\end{array}$} \\
\hline 2005-2006 & & & & \\
\hline $2006-2007$ & & & & \\
\hline 2007-2008 & & & & \\
\hline $2008-2009$ & & & & \\
\hline 2009-2010 & & & & \\
\hline $2010-2011$ & & & \multirow[t]{3}{*}{ CSB4 } & \multirow{3}{*}{$\begin{array}{l}\text { Coordenador da atenção especia- } \\
\text { lizada em saúde bucal }\end{array}$} \\
\hline 2011-2012 & \multirow[t]{3}{*}{ CSB3 } & \multirow[t]{2}{*}{ Coordenador de saúde bucal } & & \\
\hline $2012-2013$ & & & & \\
\hline 2013-2014 & & & \multirow{3}{*}{$\begin{array}{l}\text { CSB não } \\
\text { entrevistado }\end{array}$} & \multirow{3}{*}{$\begin{array}{l}\text { Coordenador da atenção especia- } \\
\text { lizada em saúde bucal }\end{array}$} \\
\hline $2014-2015$ & \multirow[t]{2}{*}{ CSB5 } & \multirow[t]{2}{*}{ Coordenador de saúde bucal } & & \\
\hline 2015-2016 & & & & \\
\hline
\end{tabular}

As entrevistas foram realizadas no próprio município, por uma única entrevistadora, e o conteúdo temático ${ }^{27}$ foi analisado segundo categorias previamente estabelecidas (quadro 2). 
Quadro 2. Categorias estabelecidas para análise das entrevistas dos coordenadores de saúde bucal de um município baiano, 2016

\begin{tabular}{ll}
\hline Categorias & Critérios para definições \\
\hline Capital cultural/escolar & Muito baixo = Analfabeto ou 10 grau incompleto; \\
& Baixo = 1ㅇg grau completo ou 20 grau incompleto; \\
& Médio = 20 grau completo ou superior incompleto; \\
& Alto = Superior completo; \\
& Alto-Baixo = Graduação em curso superior; \\
& Alto-Médio = Especialização; \\
& Alto-Alto = Mestrado/Doutorado. \\
& A partir do capital cultural/escolar e ocupação dos pais e avós. \\
Origem social & A partir da conclusão de cursos de graduação, atualização, pós-graduação \\
Formação profissional & latu sensu e stricto sensu. \\
Trajetória profissional & A partir da atuação profissional, incluindo empregos e funções exercidas. \\
Inserção e trajetória no campo burocrá- & A partir da entrada no campo burocrático, bem como cargos e funções \\
tico & ocupadas na gestão pública do município. \\
\hline
\end{tabular}

Fonte: Adaptado de Cruz $\mathbf{2 8}$

O presente estudo foi aprovado pelo Comitê de Ética em Pesquisa do Instituto de Saúde Coletiva (ISC) da Universidade Federal da Bahia (UFBA), por meio do parecer n ${ }^{0} 391.724$.

\section{Resultados}

\section{Foram realizadas entrevistas com seis}

coordenadores, três do sexo feminino e três do masculino, com idade média de 45 anos. Cinco entrevistados nasceram em municípios da Bahia: CSB3, CSB5 e CSB6, no próprio município em estudo; e CSB2 e CSB4, em cidades pequenas próximas. Apenas CSB1 nasceu no interior de Minas Gerais (quadro 3).

Quadro 3. Caracterização dos coordenadores de saúde bucal de um município baiano segundo sexo, idade e origem social (escolaridade e ocupação dos pais e avós), 2016

\begin{tabular}{|c|c|c|c|c|}
\hline Agente & Sexo & $\begin{array}{l}\text { Idade } \\
\text { (anos) }\end{array}$ & Onde nasceu & Onde estudou \\
\hline CSB1 & M & 46 & Zona urbana do interior de Minas Gerais & $\begin{array}{l}\text { Ensino fundamental em escolas públicas no município onde nasceu e } \\
\text { ensino médio em escola pública em Brasília (DF). }\end{array}$ \\
\hline CSB2 & $\mathrm{F}$ & 45 & $\begin{array}{l}\text { Cidade de pequeno porte no interior da } \\
\text { Bahia }\end{array}$ & $\begin{array}{l}\text { Ensino fundamental em colégio público na cidade onde nasceu e em } \\
\text { colégio particular em município de grande porte da Bahia; Ensino médio } \\
\text { na capital baiana. }\end{array}$ \\
\hline CSB3 & $\mathrm{F}$ & 43 & Município em estudo & $\begin{array}{l}\text { Ensino fundamental e médio em escola particular no município onde } \\
\text { nasceu. }\end{array}$ \\
\hline CSB4 & M & 42 & $\begin{array}{l}\text { Cidade de pequeno porte no interior da } \\
\text { Bahia }\end{array}$ & $\begin{array}{l}\text { Ensino fundamental em escola particular na cidade onde nasceu e } \\
\text { ensino médio na capital baiana. }\end{array}$ \\
\hline CSB5 & $\mathrm{F}$ & 36 & Município em estudo & $\begin{array}{l}\text { Ensino fundamental e ensino médio (até o } 1^{0} \text { ano) em escola particular } \\
\text { no município onde nasceu e conclusão do ensino médio em uma escola } \\
\text { particular na capital baiana. }\end{array}$ \\
\hline CSB6 & M & 59 & Município em estudo & $\begin{array}{l}\text { Ensino fundamental em escola particular e escola pública no município } \\
\text { em estudo e ensino médio em escola particular na capital baiana. }\end{array}$ \\
\hline
\end{tabular}


Quadro 3. (cont.)

\begin{tabular}{|c|c|c|c|c|}
\hline \multirow{2}{*}{ Agente } & \multicolumn{4}{|c|}{ Escolaridade e Ocupação } \\
\hline & Mãe & Pai & Avós paternos & Avós maternos \\
\hline CSB1 & $\begin{array}{l}\text { 10 grau completo; Dona de } \\
\text { casa. }\end{array}$ & $\begin{array}{l}\text { 10 grau completo; Aposen- } \\
\text { tado de um banco público. }\end{array}$ & Não há relatos na entrevista. & Não há relatos na entrevista. \\
\hline CSB2 & $\begin{array}{l}\text { 2o grau completo; Funcioná- } \\
\text { ria da educação (Secretaria } \\
\text { da Educação e professora). }\end{array}$ & $\begin{array}{l}2^{\circ} \text { grau completo; Comer- } \\
\text { ciante (posto de gasolina). }\end{array}$ & $\begin{array}{l}\text { Avô: agricultor. Não soube infor- } \\
\text { mar escolaridade, mas sabia ler e } \\
\text { escrever. Avó: era dona de casa; não } \\
\text { informa a escolaridade. }\end{array}$ & $\begin{array}{l}\text { Avô: não informa a escolaridade. } \\
\text { Político e muito influente na cidade. } \\
\text { Avó: dona de casa; não informa a } \\
\text { escolaridade. }\end{array}$ \\
\hline CSB3 & $\begin{array}{l}\text { 20 grau completo; Aposenta- } \\
\text { da pela Secretaria de Educa- } \\
\text { ção (professora). Madrasta: } \\
\text { sabia ler e escrever, mas não } \\
\text { soube informar a escolari- } \\
\text { dade. }\end{array}$ & $\begin{array}{l}\text { 20 grau completo; Comer- } \\
\text { ciante (tabacaria, posto de } \\
\text { gasolina, fazenda de café e } \\
\text { de cacau). }\end{array}$ & $\begin{array}{l}\text { Não soube informar a escolaridade } \\
\text { de ambos. }\end{array}$ & $\begin{array}{l}\text { Avô: pecuarista (fazenda de cacau). } \\
\text { Sabia ler e escrever, mas não soube } \\
\text { informar a escolaridade. Avó: sabia ler } \\
\text { e escrever, mas não soube informar a } \\
\text { escolaridade. }\end{array}$ \\
\hline CSB4 & $2^{\circ}$ grau completo, professora. & $\begin{array}{l}\text { 10 grau incompleto, Produ- } \\
\text { tor rural. }\end{array}$ & $\begin{array}{l}\text { Avô: 1o grau incompleto. Avó: 1ำ } \\
\text { grau completo. }\end{array}$ & $\begin{array}{l}\text { Avô: } 1 \text { o grau completo. Foi prefeito na } \\
\text { cidade (interior da BA). Avó: 1o grau } \\
\text { completo. Funcionária dos Correios e } \\
\text { dona de casa. }\end{array}$ \\
\hline CSB5 & $\begin{array}{l}\text { Ensino superior completo; } \\
\text { fisioterapeuta do Estado. }\end{array}$ & $\begin{array}{l}\text { Não informa a escolarida- } \\
\text { de; Comerciante. }\end{array}$ & $\begin{array}{l}\text { Avô: } 2^{\circ} \text { grau completo; produtor } \\
\text { rural (fazenda pequeno porte de } \\
\text { gado). Avó: } 2^{\circ} \text { grau completo; dona } \\
\text { de casa. }\end{array}$ & $\begin{array}{l}\text { Avô: } 2^{\circ} \text { grau completo. Fazendeiro. } \\
\text { Avó: } 2^{\circ} \text { grau completo; dona de casa } \\
\text { e assumiu a fazenda (médio porte } \\
\text { de gado leiteiro e de corte) quando o } \\
\text { marido faleceu. }\end{array}$ \\
\hline CSB6 & 1ㅇ grau completo & $\begin{array}{l}\text { Cirurgião-dentista; Profes- } \\
\text { sor de Geografia do ensino } \\
\text { médio. }\end{array}$ & $\begin{array}{l}\text { Avô: Comerciante (loja de tecidos); } \\
\text { não informa a escolaridade. Avó: } \\
\text { Tabeliã; não informa a escolaridade. }\end{array}$ & $\begin{array}{l}\text { Avô: não há relatos sobre ele na en- } \\
\text { trevista. Avó: 1o grau completo; dona } \\
\text { de casa. }\end{array}$ \\
\hline
\end{tabular}

Todos os coordenadores cursaram o Ensino Fundamental nos municípios onde nasceram. Posteriormente, foram para Salvador (BA) concluir o Ensino Médio, com exceção do CSB1, que se mudou para Brasília (DF). Apesar das idades serem próximas, pode-se observar que os mais jovens (CSB3, CSB4 e CSB5) estudaram em escolas particulares. CSB1 estudou em escolas públicas (quadro 3).

\section{Origem social}

O volume de capital cultural das mães dos coordenadores era, em sua maioria, médio, enquanto para os pais, alto. Três mães concluíram o $2^{\circ}$ grau, e uma concluiu a graduação em Fisioterapia (CSB5), sendo três delas professoras (CSB2, CSB3 e CSB4). Entre os pais, apenas um possuía $1^{\circ}$ grau incompleto (CSB1), e dois possuíam $2^{\circ}$ grau completo (CSB2 e CSB3). Em relação à ocupação, o pai do CSB6 era dentista; e, entre os demais, ressalta-se o desenvolvimento de atividades comerciais e o fato de apenas um (CSB1) não ser dono do próprio negócio (quadro 3).

De modo geral, observou-se baixo capital cultural entre os avós. Em relação aos avós paternos, somente dois agentes (CSB4 e CSB5) souberam informar a escolaridade destes. CSB1 não fez relato sobre seus avós paternos e maternos (quadro 3). Destaca-se as relações com o campo político entre os avôs de CSB2 (envolvimento com deputados) e o de CSB4 (chegou a ser prefeito do município).

\section{Formação profissional}

Todos os entrevistados graduaram em Instituições de Ensino Superior (IES) da Bahia (3 em IES públicas e 1 em IES privada) e de Minas Gerais (1 em IES pública e 1 IES privada) (quadro 4). 
Quadro 4. Caracterização da formação profissional e trajetória no campo burocrático dos coordenadores de saúde bucal de um município baiano, em ordem cronológica, 1997-2016

\begin{tabular}{|c|c|c|}
\hline $\begin{array}{l}\text { Agente, IES e ano da } \\
\text { Graduação }\end{array}$ & Pós-Graduação (Especialidade e ano) & Trajetória no campo burocrático \\
\hline CSB6 - Pública - 1984 & Sem especialização & 1997-1998: Coordenador da Divisão de Odontologia \\
\hline CSB1 - Pública - 1984 & Especialização em Prótese (1995) & $\begin{array}{l}\text { 1998-2004: Coordenador de saúde bucal } \\
\text { 2004-2010: Coordenador da atenção especializada em } \\
\text { saúde bucal }\end{array}$ \\
\hline CSB2 - Pública - 1994 & $\begin{array}{l}\text { Ortodontia - Curso Typodont (1996); } \\
\text { Especialização em Dentística Restauradora (1997); } \\
\text { Especialização em Saúde Pública (1998); } \\
\text { Mestrado Profissional em Saúde Coletiva (2009). } \\
\text { Especialização em Saúde Pública (1999). }\end{array}$ & $\begin{array}{l}\text { 2004-2011: Coordenadora de saúde bucal } \\
\text { 2007-2011: Supervisora da atenção básica } \\
\text { 2011-2014: Diretora da Atenção Básica } \\
\text { 2014-2016: Coordenadora da Auditoria }\end{array}$ \\
\hline CSB3 - Privada - 1995 & $\begin{array}{l}\text { Aperfeiçoamento em Prótese e Dentística (2003); } \\
\text { Mestrado Profissional em Saúde Coletiva (2009); } \\
\text { Aperfeiçoamento em Cirurgia-Bucomaxilofacial (2002 e } \\
\text { 2006). }\end{array}$ & $\begin{array}{l}\text { 2011-2015: Coordenação de Saúde Bucal junto com a Dire- } \\
\text { toria de Atenção Básica } \\
\text { 2015-2016: Diretora da Regulação }\end{array}$ \\
\hline CSB4 - Pública - 1996 & $\begin{array}{l}\text { Aperfeiçoamento em Implantodontia (2007); } \\
\text { Especialização em Periodontia (2003); } \\
\text { Especialização em Saúde Coletiva (2006); } \\
\text { Mestrado em Odontologia (2012). }\end{array}$ & $\begin{array}{l}\text { 2010-2013: Coordenador de atenção especializada em } \\
\text { saúde bucal }\end{array}$ \\
\hline CSB5 - Privada - 2005 & Especialização em Saúde Coletiva (2006) & $\begin{array}{l}\text { 2011-2015: Apoiadora Institucional/Atenção Básica } \\
\text { 2015-2016: Coordenadora de Saúde Bucal }\end{array}$ \\
\hline
\end{tabular}

Fonte: Pesquisa de campo, 2016

Em relação à escolha pela Odontologia, o discurso de três agentes revela uma influência, direta ou indireta, da família. Para CSB2, a escolha esteve ligada à sua irmã. CSB3 e CSB6 atribuíram suas escolhas à vivência em estabelecimento de familiares que vendia materiais odontológicos e no consultório do pai dentista, respectivamente.

Na verdade, até hoje me pergunto porque escolhi Odontologia, viu?! Acho que foi muito influência da minha irmã. [...] E fiquei naquela influência dela e resolvi fazer Odontologia. E aí foi que gostei do curso [...]. (CSB2/45 anos).

[...] essa irmã de minha mãe tem uma dental junto com esse meu tio e, desde pequena, eu vivia lá na dental e achava fantástico aqueles dentes e era gesso, pesava gesso e achava aquilo fantástico [...]. (CSB3/43 anos).

É importante acrescentar a escolha profissional pela Odontologia ao invés da Medicina por parte do CSB1. Esse caso revela o que Bourdieu ${ }^{14}$ denomina de uma economia econômica em virtude da duração do curso. Essa lógica econômica deve ter sido incorporada como disposição devido à sua trajetória social (único que cursou escola pública e cujo pai não era proprietário do próprio negócio) e relaciona-se com a sua tomada de decisão:

[...] falo que não fui médico talvez porque precisava formar, sabe? [...] gosto de medicina e me identifico muito bem com a saúde de uma forma geral. E a odontologia, acho que porque naquele momento eram 4 anos; quis formar logo para ir cuidar de minha vida. (CSB1/46 anos).

O investimento na qualificação profissional foi mencionado pela maioria dos entrevistados (quadro 4). Observou-se que apenas CSB6 não realizou especialização, argumentando a necessidade de trabalhar e sustentar a família. Lógica econômica semelhante àquela retratada 
na escolha profissional do CSB1. Destaca-se que, nos anos 1990, a formação especializada ainda era rara no campo odontológico, principalmente na área de saúde coletiva.

[...] Não fiquei em Salvador, me formei e voltei para cá por necessidade de trabalho mesmo. E logo após, veio o casamento, veio filho, então não tive nem oportunidade de fazer um curso de pós-graduação, apesar de que fui contemplado com uma vaga em um curso de especialização em São Paulo, Bauru, mas não houve condições... (CSB1/46 anos).

CSB1, durante a graduação, identificou-se com uma área que justifica sua escolha para especialização.

[...] desde a faculdade, sou monitor de prótese. [...] pela parte de arte, essa parte minuciosa e, hoje, a parte de estética, sorriso, de posição de dente, de tudo. Sou meio apaixonado por isso. (CSB1/46 anos).

Entre os coordenadores que cursaram alguma pós-graduação, apenas um não a fez na área de clínicas odontológicas, ratificando a identificação com a clínica e a dominação dessas especialidades no espaço da saúde bucal. Alguns agentes afirmaram que a busca pela titulação foi por afinidade pelas áreas clínicas. CSB4 justificou sua escolha por uma necessidade percebida na sua prática no consultório particular. Esse mesmo agente apontou ainda que a escolha pela especialização em Saúde Coletiva foi circunstancial.

[...] acabei fazendo, também, outros cursos porque, embora goste muito da saúde coletiva, me identifico muito com a clínica [...] e acabei fazendo outros cursos de atualização de prótese, de estética [...]. (CSB3/43 anos).

[...] fiz primeiro Periodontia, Saúde Coletiva e depois Implantodontia. Periodontia para a clínica, consultório particular e etc., Saúde Coletiva fiz me preparando para o concurso, tem que ter essa especialidade, trabalho aqui, nem pensava em ser coordenador ainda, fiz por esse motivo [...]. (CSB4/42 anos).

A escolha da especialização por CSB2 pode estar relacionada com a questão do gênero ou também com a lógica econômica. Ela afirma que abdicou da ortodontia por causa da transferência (de emprego) do marido, entretanto, isso não a impediu de realizar a especialização na capital (quadro 4). Outro elemento importante nas decisões acerca das especializações foi a rede de relações. Para CSB2, CSB3 e CSB4, familiares (cunhada e esposa), amigos e colegas de turma que apresentaram possibilidades de pós-graduações os incentivaram à qualificação profissional:

E aí com o contato com elas [duas colegas da graduação] eu fui saber como é que estava funcionando e como era o PSF [no município em estudo]. E acho que isso foi umas das molas propulsoras que me incentivou a fazer o curso [...]. (CSB2/45 anos).

Já a escolha da especialização em Saúde Coletiva de CSB6 não pareceu estar atrelada a uma lacuna da graduação.

Percebeu-se um alto nível de especialização entre os entrevistados, destacando-se o fato de três possuírem o título de mestre (CSB2 e CSB3 em Saúde Coletiva e CSB4 em Odontologia Clínica).

\section{Trajetória profissional e inserção no campo burocrático}

A análise da trajetória profissional revelou que todos os agentes desenvolveram atividades com dupla inserção, ou seja, atuaram no SUS e no setor privado (consultório odontológico próprio ou de terceiros). No âmbito do SUS, destaca-se que apenas CSB1 e CSB6 não atuaram na ESF.

Sobre a inserção na ESF, chama a atenção o período de permanência, de modo que CSB2, CSB3 e CSB4 atuaram em equipes do município por, pelo menos, cinco anos. CSB5 foi 
quem permaneceu menos tempo na ESF local, sendo incorporada à equipe de apoiadores institucionais, e a única que não atuava, naquele momento, em consultório particular.

$\mathrm{O}$ primeiro a ser incorporado à equipe gestora da Secretaria Municipal de Saúde foi CSB6, no momento inicial do período analisado. Apesar de não ter qualquer experiência prévia em gestão, foi convidado a assumir a Divisão de Odontologia em virtude da rede de relações que possuía:

[...] inicialmente quando houve o processo da municipalização o primeiro secretário de saúde [...] e como nós trabalhávamos no centro médico odontológico no mesmo andar, em salas próximas, eu tinha muita amizade com ele, sempre tinha oportunidade de conversar... [...] Então, quando ele foi convidado para ser o secretário de saúde [...], também me deu a incumbência de ajudá-lo nessa gestão dele como secretário de saúde e, naquela época, eu disse que não entendia nada de gestão pública e ele falou: 'Eu estou sendo secretário de saúde pela primeira vez'. Eu aceitei na iminência de que se não gostasse eu teria total liberdade de sair. (CBS6/59 anos).

Foi possível perceber, como outros autores ${ }^{\mathbf{1 8}, \mathbf{1 9}}$, uma conversão de capital militante em capital burocrático por CSB1 e CSB4 nas suas participações em Diretório Acadêmico ou em entidade de classe (Associação Brasileira de Odontologia - ABO, Conselho Regional de Odontologia - CRO-BA) assumindo, inclusive, cargos de direção, até mesmo presidência, fato considerado pelo agente CSB4 como uma 'disposição natural'.

Entrevistador - [...] Como foi ser coordenador, [...] para você?

CSB4 - Para mim, eu achei até uma coisa natural porque como sempre fui muito envolvido com a questão da classe odontológica, eu fui presidente da ABO. (CSB4/42 anos).

Cabe destacar que a incorporação do CSB4 à equipe gestora foi a mais tardia entre os profissionais que já atuavam na rede de serviços do SUS no município, mas também se deu por sua rede de relações:

[...] nessa época eu estava muito ligado a [...] que era vereador na época, [...] meu irmão é casado com a irmã dele, então desde pequeno a gente se conhece [...]. Na época que ele se elegeu como vereador, tem essa questão de cargo lá, acho que conversou com [...] na época era Secretária de Saúde [...] e as coisas foram confluindo. [...] E eu virei coordenador do CEO... (CSB4/42 anos).

Ainda sobre o CSB4, os achados apontam tomadas de posição articuladas e de caráter empreendedor explícitas na realização da especialização em Saúde Coletiva e reabertura do próprio consultório. Ressalta-se, ainda, sua curta permanência na coordenação do CEO. Sua saída do campo burocrático articulou-se com sua entrada no campo científico, confirmando uma disposição revelada na família (mãe professora) e pessoal desde quando ministrava aulas para o ensino médio.

No último ano de faculdade, eu consegui estágio numa escola pública lá de Salvador, [...] dando aula de Ciências. [...] Logo em seguida que eu terminei o curso de Odonto, dois dias depois eu estava dando aula em [cita nome de município próximo ao município de estudo] no Ensino Médio... (CSB4/42 anos).

Por fim, a análise dos cargos ocupados no campo burocrático pelos entrevistados revela, entre a maioria, uma trajetória ascendente ao interior desse espaço, já que CSB2, CSB3 e CSB5 assumiram cargos que acumulam algum poder na organização do SUS municipal. O fato de CSB4 e CSB6 não terem construído uma trajetória no campo burocrático aponta para uma possível relação entre a entrada nesse campo por acumulação técnica-profissional e por meio da rede de relações, bem como pelo maior investimento posterior no setor privado odontológico. Chama a atenção que ambos foram coordenadores do centro especializado, 
sendo esta área com maior interface com a clínica e a prática no setor privado.

\section{Os agentes e a política de saúde bu- cal no município}

O pioneirismo do município estudado na inserção do dentista na Equipe de Saúde Bucal/ Programa Saúde da Família (ESB/PSF), especialmente porque em 1998 não existia um financiamento direcionado para isso, foi relatado pelo CSB6. Visando qualificar o processo de implantação das ESB, CSB6 procurou auxílio de uma docente da UFBA, destacando tal articulação como fator colaborador na construção das ações municipais.

[...] eu, o próprio secretário de saúde [na épo$\mathrm{ca}$, e outras pessoas pensaram]. Por que não pensar no papel do cirurgião-dentista na equipe de saúde da família? Ainda que não houvesse financiamento para o cirurgião-dentista, porque naquela época não tinha, mas [o município em estudo] foi pioneiro. Então, levou essa ideia ao prefeito, o prefeito achou muito boa, né? (CSB6/59 anos).

[...] primeira seleção que foi feita aqui para $o$ PSF [...] foi quando [a docente da UFBA] veio. Ela já veio para fazer a seleção [...] ela e mais outra colega [...] fariam a questão da seleção de acordo com o perfil das pessoas que poderiam ser inseridas no contexto do cirurgião-dentista na Saúde da Família. [...] deu um ponta pé inicial. (CSB6/59 anos).

A inserção do dentista, antes de qualquer formulação por parte do Ministério da Saúde, também, é destacada pelo CSB1, que antes de compor a equipe gestora era membro do Conselho Municipal de Saúde como representante do Conselho Regional de Odontologia (CRO-BA).

Era a gente mesmo [que construía a política], cada um era responsável e tudo o que a gente falava ou pensava era colocado em prática. [...] quando a gente estava lá no Conselho, a gente já exigia [dentista no PSF]. Quando começaram a falar de equipe de saúde da família, nós já colocamos. (CSB1/46 anos).

CSB1, diante desse processo inicial de organização da atenção à saúde bucal no município, destacou a formulação de projetos como a Policlínica de Odontologia Especializada (POE), revelando outra 'inovação' no município, um interesse em lutar pelo interesse público.

[...] não podia ficar sem [serviço especializado]. Porque não adiantava a gente, na discussão daquela época, ficar ali e a medicina evoluindo, estava montando e tudo. Então, a Odontologia tinha que ir junto, sabe? Foi uma luta grande ali... 'Ah, vamos fazer um Centro Especializado', por exemplo [...] 'Ah, mas é caro'; sim..., mas, se tem dinheiro para ressonância, tomografia... Tem que criar! $E$ a Odontologia foi junto a este pensamento porque não poderia ficar por fora. (CSB1/46 anos).

A articulação dos coordenadores com o campo científico, como mencionado pelo CSB6, também é destacada pelo CSB1. Nesse particular, o apoio do ISC/UFBA, especialmente da Residência Multiprofissional/Saúde da Família, foi fundamental.

[...] tive apoio de muitas pessoas, a gente fez uma parceria muito boa com o Instituto de Saúde Coletiva, com os Residentes [da UFBA] [...], acho que foi muito interessante. Eu conhecia a realidade do serviço, sabia das dificuldades, das necessidades. Eu precisava de apoio porque eu não tinha pernas para fazer tudo sozinha. Foi à época que vieram os Residentes [...] acho que foi um momento bem interessante, foi uma contribuição muito boa... (CSB2/45 anos).

A parceria com o ISC/UFBA foi importante ainda para a construção de um protocolo que articulou a atenção básica e a policlínica. Os relatos da CSB2 revelam ainda que o modelo de atenção preconizado era o da vigilância da saúde. 
[...] Eu acho que o papel da coordenação é impulsionar, é dar um norte para as Unidades [...] de acordo com aquele modelo de saúde que quer implantar [...] quando eu assumi a coordenação de saúde bucal foi uma das coisas que eu identifiquei primeiro, essa falta [do protocolo], não no intuito em estar engessando o trabalho das pessoas, mas no intuito de dar um norte [...] não fugir daquele modelo de vigilância à saúde [...] a gente sabe que cada profissional vem de uma faculdade diferente, não são todos os cursos que formam com essa visão... (CSB2/45 anos).

A educação permanente em saúde foi um recurso necessário e priorizado pela gestão, tanto na etapa de expansão da ESB/ESF quanto no momento de transformação do quadro de profissionais da saúde bucal como descrito na fala da CSB3 a seguir. Era importante para o avanço da saúde bucal a perpetuação do processo estabelecido:

[...] nós tivemos então, como eu disse, uma saída de vários profissionais com a questão do concurso. Então, hoje, 90\% dos profissionais que são [...] do concurso; não tinham nenhuma experiência, nenhuma vivência na saúde pública, profissionais recém-formados. Então, achei até interessante pensar [...] e garantir todo o servico, dar continuidade [...] gente investiu naquele momento toda a Atenção Básica em educação permanente [...] trabalhando com troca de experiências a todo momento, [...]e acho que os profissionais foram crescendo realmente [...]. (CSB3/43 anos).

A articulação entre a prefeitura, instituições de ensino superior e associações de classe configurou as condições de possibilidade nesse 'espaço dos possíveis' para garantir a atenção especializada, em 1999, que foi considerada pelo agente CSB4 como o ‘embrião' do CEO no município.

[...] a prefeitura não tinha espaço [para construção da $\mathrm{POE}$ ], a $\mathrm{ABO}$ não tinha espaço e o único espaço que poderia ter era o da Universidade Estadual [...] na colocação do convênio [...] a ABO entraria com cinco consultórios odontológicos, a prefeitura entraria com dois consultórios odontológicos e a Universidade com um, ficaria um espaço com 8 consultórios. A prefeitura se comprometia a fazer um concurso para dentistas trabalharem nesse local que se chamava Policlínica de Odontologia Especializada e a Universidade tinha o espaço e a gente tinha a obrigação de atender os servidores da Universidade e foi lá que começou mesmo, o embrião do CEO. (CSB4/42 anos).

Apesar do avanço na formulação e implantação da política de saúde bucal, da direcionalidade e continuidade das ações da equipe gestora, a falta de recursos financeiros tornou-se, mais recentemente, entre 2015 e 2016, uma variável importante para o impasse na expansão das ESB, constituindo-se em obstáculo a sua manutenção. Observa-se uma dificuldade na ampliação de novos serviços na atenção básica e no CEO:

[...] para a gente implantar a equipe hoje está muito difícil, provavelmente a gente não vai conseguir [...] porque a dificuldade é muito grande, a cobrança é muito grande, mas infelizmente não tem como implantar. Como o município aqui, ele já repassa $25 \%$ de recurso, a gente sabe que a obrigação é $15 \%$, e a gente sabe que ainda está insuficiente, então assim [...] a grande dificuldade mesmo é o recurso [...]. (CSB5/36 anos).

[...] na época [em] que eu fui coordenador [do CEO], o grande problema era aquisição de materiais e manutenção de equipamentos. Porque a gente conseguiu dentistas, a gente conseguiu implementar [...] Só que assim, as coisas eram muito lentas e, assim, apesar disso tudo, a gente viu que chegou certo momento que as coisas não avançavam mais... (CSB4/42 anos).

Avanços diferenciados na implantação da política também estão atrelados à compreensão entre os agentes dos objetivos que estão em jogo e como desempenharão a luta em defesa desses propósitos. 


\section{Discussão}

A implementação das políticas de saúde bucal no município entre 1997 e 2015, por um lado, foi resultado da conjugação das condições históricas de possibilidade no âmbito municipal no final dos anos 1990 e no âmbito nacional a partir de 2003. Por outro, também foi resultado das trajetórias e disposições políticas e militantes dos seus coordenadores, ainda que com diferenças nos seus distintos capitais.

Os agentes sociais que coordenaram a saúde bucal do município estudado tiveram, em sua maioria, uma trajetória de acumulação de capital específico a partir dos cargos ocupados no período. A inserção desses agentes na equipe gestora foi influenciada tanto pelas disposições políticas ou militantes quanto pela rede de relações do tipo familiar ou política. O reconhecimento do trabalho desempenhado na ESF local pelo gestor municipal parece também ter influenciado na ocupação dessa posição.

O investimento na qualificação profissional pode ser um aspecto diferenciador para os coordenadores desse município, apesar da pós-graduação em saúde coletiva, para muitos, só ocorrer porque representava maior potencialidade de inserção na ESF. Trata-se, portanto, de uma equipe gestora qualificada tecnicamente, ainda que predominando nas escolhas dos CSB a manutenção do exercício profissional atrelado à prática clínica, mesmo em um município avançado na implementação das ações públicas de saúde bucal.

Entende-se que a formação em saúde coletiva pode proporcionar um maior empoderamento dos agentes e possibilitar melhor condução das ações de saúde, ou seja, maior capacidade de governo pode tornar a implementação das políticas mais eficiente ${ }^{\mathbf{1 3}}$. Por outro lado, a conformação de equipe gestora da saúde com formação e experiência de gestão diversificada pode resultar impasses e falta de articulação ao interior da gestão ${ }^{12}$.

As diferenças de características dos gestores (secretário ou equipe dirigente) podem, ainda, evidenciar variáveis que venham a prejudicar a formulação e implantação das políticas de saúde ${ }^{\mathbf{1 3} 29}$. O aumento da capacidade do gestor municipal na implantação das políticas de saúde bucal está relacionado com o capital político desse agente dentro do campo burocrático ${ }^{\mathbf{1 2}}$.

Também se ressalta a permanência de, pelo menos, três anos dos CSB na gestão, o que pode explicar, em parte, a possibilidade de inovação e de continuidade da implementação da política de saúde bucal local. Há evidências de que uma constante mudança dos gestores e a pouca permanência nos cargos implicam fragilidade na implementação das políticas e sugere, igualmente, falta de compromisso e de interesse quanto ao SUS como política de Estado ${ }^{29}$.

Merece ainda ser destacado o fato de que a maioria dos coordenadores era proveniente da ESF local. A articulação da experiência na rede assistencial com o perfil técnico configura a 'valorização da prata da casa'30. Além disso, os coordenadores apresentavam um envolvimento emocional com o bom desenvolvimento das ações de saúde bucal, buscando atuar com dedicação, criatividade e iniciativa, o que caracterizaria o empreendedorismo militante ${ }^{31}$. Outra característica foi a manutenção pelos CSB da atuação em clínicas particulares (dupla militância), o que é sempre um obstáculo para a gestão e pode suscitar tomadas de posição conflitantes ${ }^{32}$.

O investimento na qualificação profissional em espaços em que há uma grande força militante e a inserção política dentro de grupos organizados também caracteriza o empreendedorismo militante ${ }^{31}$. A presença de atores atuantes no campo burocrático macropolítico, que já passaram por outros espaços no micropolítico, traz uma perspectiva de construção de uma nova burocracia, em que são fundamentais para uma implementação de política de saúde por exemplo.

$\mathrm{O}$ investimento em educação permanente favoreceu a continuidade do que já estava implantado, assegurando a perpetuação das conquistas no que tange à política de saúde bucal. Tal evidência corrobora o estudo de Chaves e Vieira-da-Silva ${ }^{32}$, no qual municípios que obtiveram suporte da gestão e realizavam 'oficinas de sensibilização e 
capacitação dos profissionais' alcançaram melhores resultados.

$\mathrm{O}$ apoio do prefeito, desde as primeiras propostas para a saúde bucal, colaborou para a formulação e para o desenvolvimento da política, inclusive direcionando para áreas mais vulneráveis da zona rural. $\mathrm{O}$ apoio do gestor municipal e da saúde foi ressaltado por quase todos agentes que relataram a importância de o governo estar a favor para o desenvolvimento das políticas de saúde acontecer, aspecto também percebido em outros estudos ${ }^{12,13,30}$ como relevante para a implementação de políticas de saúde.

Estudo realizado anteriormente no mesmo município revelou a importância da gestão para o desenvolvimento do setor da saúde, pois se tratava de um governo de ruptura com 'amarras tradicionais encontradas nos interiores baianos', elegendo um prefeito que promoveu a existência de uma saúde pública de destaque ${ }^{31}$.

A PNSB de 2004 trouxe possibilidades de expansão da rede de atenção à saúde bucal devido ao repasse financeiro. Contudo, em 2004, as principais proposições da PNSB já estavam implantadas no município estudado. Desse modo, ela foi incorporada ao projeto de saúde bucal em curso no município, fato que destoa do estudo na capital baiana onde não houve a incorporação da PNSB à política municipal12. Ou seja, no município em questão a PNSB teve papel de fomentar aquilo que já vinha sendo desenvolvido, seja na atenção especializada, seja na atenção primária, enquanto na capital baiana teve papel indutor, em especial na atenção primária, pois Salvador também contava com um centro de referência de odontologia.

Contudo, o aumento de recursos de custeio com a ampliação do número de ESB, por exemplo, não foi suficiente para impedir que, no atual momento histórico, a maior dificuldade enfrentada seja relacionada com a dimensão financeira. A literatura, também, aponta a falta de recursos para a manutenção da rede de saúde bucal como aspecto que impossibilita o avanço da política, sendo importante que o repasse de recursos financeiros envolva, também, os níveis estadual e federal ${ }^{33}$. No caso da Bahia, destaca-se a ausência de financiamento estadual específico para a saúde bucal, bem como forte sobrecarga dos municípios no financiamento do SUS, levando-os a fazer escolhas entre políticas prioritárias.

\section{Considerações finais}

O município estudado configura-se como caso exemplar na implementação da política de saúde bucal, que, com outras experiências municipais, inspirou a formulação de algumas iniciativas federais. A análise das trajetórias social e profissional desses coordenadores de saúde bucal reforçou a importância dos agentes sociais municipais na implantação de políticas de saúde bucal. Além das trajetórias social e profissional, a capacidade técnica dos agentes, $\mathrm{o}$ apoio da gestão local e do prefeito, o apoio de associações específicas e instituições de ensino superior foram fatores importantes para o avanço e reorganização da atenção à saúde no período estudado.

A principal lacuna deste estudo foi a análise de um caso único, bem como a limitação a um determinado período histórico.

Recomenda-se a realização de análise semelhante em outros municípios para a identificação de possíveis regularidades e análise da atuação dos agentes sociais que possam contribuir para a explicação dos diferentes graus de implementação das políticas de saúde bucal no País.

\section{Colaboradores}

ASC elaborou o artigo a partir de seu Trabalho de Conclusão de Curso (TCC) de graduação. DNC, orientadora do TCC, contribuiu para a elaboração e desenvolvimento do projeto de pesquisa, análise e interpretação de dados e revisão crítica do manuscrito. SGB concebeu e coordenou o projeto de pesquisa, contribuiu para a análise e interpretação dos dados, bem como para a revisão crítica final do manuscrito. TRAR e SCLC contribuíram para a interpretação dos dados e revisão crítica do manuscrito. 


\section{Referências}

1. Rodrigues MMA. Políticas Públicas. São Paulo: Publifolha; 2011.

2. Weber M. Conceitos Sociológicos Fundamentais. Covilhã: LusoSofia; 2010.

3. Paim JS. Saúde, Política e Reforma Sanitária. Salvador: UFBA; 2002.

4. Paim JS. Políticas de Saúde no Brasil. In: Rouquayrol MZ, Almeida Filho N. Epidemiologia \& Saúde. Rio de Janeiro: MEDSI; 2003. cap. 20. p. 587-603.

5. Brasil. Lei ${ }^{\circ} 8080$ de 19 de setembro de 1990. Dispõe sobre as condições para a promoção, proteção e recuperação da saúde, a organização e o funcionamento dos serviços correspondentes e dá outras providências. Diário Oficial da União. 19 Set 1990.

6. Teixeira C. Os princípios do Sistema Único de Saúde. In: Conferências Municipal e Estadual de Saúde; 2011 jun. Salvador: CMES; 2011 [acesso em 2014 nov 17]. Disponível em: https://www.almg.gov.br/export/ sites/default/acompanhe/eventos/hotsites/2016/encontro_internacional_saude/documentos/textos_referencia/07_principios_sistema_unico_saude.pdf.

7. Piola SF, Barros ED, Nogueira RP, et al. Vinte anos da Constituição de 1988: o que significaram para a saúde da população brasileira. In: Políticas Sociais: acompanhamento e análise: vinte anos da Constituição Federal. Brasília, DF: Ipea; 2010. p. 97-174.

8. Brasil. Lei n ${ }^{\circ} 10.216$ de 6 de abril de 2001. Dispõe sobre a proteção e os direitos das pessoas portadoras de transtornos mentais e redireciona o modelo assistencial em saúde mental. Diário Oficial da União. 6 Abr 2001.

9. Brasil. Ministério da Saúde. Secretaria de Atenção à Saúde. Departamento de Ações Programáticas Estratégicas. Política nacional de atenção integral à saúde da mulher: princípios e diretrizes, para o período compreendido entre os anos de 2004 e 2007. Brasília, DF: MS; 2004.

10. Brasil. Ministério da Saúde. Secretaria de Atenção à Saúde. Política nacional de atenção às urgências. Brasília, DF: MS; 2003.

11. Brasil. Ministério da Saúde. Secretaria de Atenção à Saúde. Departamento de Atenção Básica. Coordenação Nacional de Saúde Bucal. Diretrizes da Política Nacional de Saúde Bucal. Brasília, DF: MS; 2004.

12. Soares CLM, Paim JS. Aspectos críticos para implementação da política de saúde bucal no Município de Salvador, Bahia, Brasil. Cad. Saúde Pública. 2011; 27(5):966-974.

13. Rossi TRA, Chaves SCL. Implementação da Atenção Especializada em Saúde Bucal em dois municípios da Bahia/Brasil. Saúde debate. 2015; 39(esp):196-206.

14. Bourdieu P. Razões práticas: sobre a teoria da ação. Campinas: Papirus; 1996.

15. Yin RK. Estudo de Caso: Planejamento e Métodos. Porto Alegre: Bookman; 2015.

16. Pinell P. Análise Sociológica das Políticas de Saúde. Rio de Janeiro: Fiocruz; 2011.

17. Vieira-da-Silva LM, Pinell P. The genesis of collective health in Brazil. Sociol Health Illness. 2014; 36(3):432446.

18. Barros SG, Vieira-da-Silva LM. The genesis of the AIDS policy and AIDS Space in Brazil (1981-1989). Rev Saúde Pública. 2016; 50(43):1-14.

19. Costa-Souza J, Vieira-da-Silva LM, Pinell P. A socio-historical approach to policy analysis: the case of the Brazilian Workers? Food Policy. Cad. Saúde Pública. 2018; 34(1):1-15. 
20. Rossi TRA. Produção social das políticas de saúde bucal no Brasil [tese]. Salvador: UFBA/ISC; 2016. $380 \mathrm{p}$.

21. Soares CLM. A constituição da saúde bucal coletiva no Brasil [tese]. Salvador: UFBA/ISC; 2014. 179 p.

22. Barros SG. A política nacional de luta contra a AIDS e o espaço AIDS no Brasil [tese]. Salvador: UFBA/ ISC; 2013.

23. Barros SG, Vieira-da-Silva LM. A terapia antirretroviral combinada, a política de controle da Aids e as transformações do Espaço Aids no Brasil dos anos 1990. Saúde debate. 2017; 41(esp3):114-128.

24. Bourdieu P. As Regras da Arte: gênese e estrutura do campo literário. São Paulo: Companhia das Letras; 1996.

25. Calado, GS. A inserção da equipe de saúde bucal no Programa de Saúde da Família: Principais Avanços e Desafios [dissertação]. Rio de Janeiro: Fiocruz/Ensp; 2002. $137 \mathrm{p}$

26. Barros SG, Cangussu MCT, Cruz DN, et al. Impacto da implantação das equipes de saúde bucal na estratégia saúde da família em dois municípios do estado da Bahia. Rev Saúde Colet UEFS. 2016; 6(2):37-42.

27. Gomes R. Análise e interpretação de dados de pesquisa qualitativa. In: Minayo MSC, organizadora. Pesquisa social: Teoria, método e criatividade. Petrópolis: Vozes; 2009.
28. Cruz DN. Desigualdades na utilização de serviços odontológicos: posição e tomadas de posição no espaço social [tese]. Salvador: UFBA/ISC; 2005. p. 156.

29. Cecilio LCO, Andreazza R, Souza ALM, et al. O gestor municipal na atual etapa de implantação do SUS: características e desafios. RECIIS. 2007; 1(2):200-207.

30. Coelho TCB, Paim JS. Processo decisório e práticas de gestão: dirigindo a Secretaria da Saúde do Estado da Bahia, Brasil. Cad. Saúde Pública. 2005; 21(5):13731382.

31. Goulart FAA. Experiências em saúde da família: cada caso é um caso? [tese]. Rio de Janeiro: Fiocruz/Ensp; 2002.

32. Chaves SCL, Silva LMV. As práticas profissionais no campo público de atenção à saúde bucal: o caso de dois municípios da Bahia. Ciênc. Saúde Colet. 2007; 12(6):1697-1710.

33. Martelli PJL. Política Nacional de Saúde Bucal, da teoria à prática: um estudo de caso acerca de sua implantação em Recife-PE no período 2000 a 2007 [tese]. Recife: Fiocruz/CPQAM; 2010.

Recebido em 14/07/2018

Aprovado em 10/10/2018

Conflito de interesses: inexistente

Suporte financeiro: Fundação de Amparo à Pesquisa do Estado da Bahia (Fapesb) 